\title{
Actinobaculum urinale sp. nov., from human urine
}

Correspondence

Val Hall

hallv@cardiff.ac.uk

\section{Val Hall, ${ }^{1}$ Matthew D. Collins, ${ }^{2}$ Roger A. Hutson, ${ }^{2}$ Enevold Falsen, ${ }^{3}$ Elisabeth Inganäs ${ }^{3}$ and Brian I. Duerden ${ }^{1}$}

\author{
${ }^{1}$ Anaerobe Reference Unit, PHLS, University Hospital of Wales, Cardiff CF14 4XW, UK \\ ${ }^{2}$ School of Food Biosciences, University of Reading, Reading, UK \\ ${ }^{3}$ Culture Collection, Department of Clinical Bacteriology, University of Göteborg, Göteborg, \\ Sweden
}

\begin{abstract}
A hitherto undescribed Actinomyces-like bacterium was isolated from human urine. Based on its biochemical characteristics, the unidentified bacterium did not correspond to any currently described Actinomyces species or related taxa. Comparative 16S rRNA gene sequencing showed that the unknown bacterium exhibits a specific phylogenetic association with the genus Actinobaculum, but a sequence divergence of $>5 \%$ from the two currently recognized members of this genus, Actinobaculum schaalii and Actinobaculum suis, demonstrates that it represents a distinct species. Based on both phenotypic and 16S rRNA gene sequence considerations, it is proposed that the unknown bacterium from urine should be classified as a novel species, Actinobaculum urinale sp. nov. The type strain of Actinobaculum urinale is CCUG $46093^{\top}$ $\left(=\right.$ CIP $\left.107424^{\top}\right)$.
\end{abstract}

The genus Actinobaculum Lawson et al. 1997 forms a distinct subline, related to but distinct from the genera Actinomyces, Arcanobacterium and Mobiluncus. The genus Actinobaculum was proposed to accommodate organisms previously designated as Actinomyces suis, and also some Actinomyceslike organisms originating from human sources (Lawson et al., 1997). Currently, two species, Actinobaculum suis and Actinobaculum schaalii, are recognized in this genus; Actinobaculum suis, the type species of the genus, is an established pathogen of pigs and has had a chequered taxonomic history, having been assigned to a variety of genera including Corynebacterium, Eubacterium and Actinomyces (Wegienek \& Reddy, 1982). The second species within the genus, Actinobaculum schaalii, has been recovered from human clinical specimens such as blood and urine, but its pathogenic potential remains unknown. In recent years, there has been increased interest in Actinomyces and related organisms as possible opportunistic human pathogens, and a great variety of novel species have been described from clinical specimens, where they are associated with disease and/or occur as mucosal contaminants (e.g. Collins et al., 2000; Hall et al., 1999, 2001; Nikolaitchouk et al., 2000; Schaal, 1998; Wüst et al., 1995). During the course of an ongoing study of clinical isolates of Actinomyces and related taxa from human sources (Hall et al., 1999, 2001), we have characterized a hitherto unknown Actinobaculum-like organism from urine. Based on both phenotypic and phylogenetic evidence, we propose

The GenBank accession number for the 16S rRNA gene sequence of CCUG $46093^{\top}$ is AJ439453. a novel species of the genus Actinobaculum, with the name Actinobaculum urinale sp. nov.

Strain $\mathrm{R}^{2422^{\mathrm{T}}}$ was isolated in 1995 in Worthing, West Sussex, UK, from an anaerobic culture of urine from a human female with pyuria, after repeated urine specimens from this patient yielded no bacterial growth under aerobic conditions. The isolate grew poorly in air plus $5 \% \mathrm{CO}_{2}$, but failed to grow aerobically and was considered to be clinically significant. Strain $\mathrm{R} 9242^{\mathrm{T}}$ has been deposited in the Culture Collection of the University of Göteborg under the accession number CCUG $46093^{\mathrm{T}}$. The strain was cultured on Columbia agar (Difco) supplemented with $5 \%$ horse blood at $37^{\circ} \mathrm{C}$, under anaerobic conditions. The strain was characterized biochemically by using the API Rapid ID 32Strep, API Rapid ID 32A, API Coryne and API ZYM systems, according to the manufacturer's instructions (bioMérieux). Volatile and non-volatile end products of glucose metabolism were detected by GLC (Holdeman et al., 1977). Long-chain cellular fatty acids were analysed as described by Kämpfer \& Kroppenstedt (1996). The 16S rRNA gene of the isolate was amplified by PCR and sequenced directly, using a Taq DyeDeoxy Terminator Cycle Sequencing kit and a model 373A automatic DNA sequencer (both from Applied Biosystems). The closest known relatives of the new isolate were determined by performing database searches. These sequences, and those of other known related strains, were retrieved from GenBank and aligned with the newly determined sequence using the program DNATools (Rasmussen, 1995). The resulting multiple sequence alignment was corrected manually, and a distance matrix was calculated with the programs PRETTY and DNADIST, using Kimura's 
two-parameter correction (Felsenstein, 1989). A phylogenetic tree was constructed according to the neighbourjoining method with the program NEIGHBOR (Felsenstein, 1989). The stability of the groupings was estimated by bootstrap analysis (500 replications) using the programs DNABOOT, DNADIST, NEIGHBOR and CONSENSE (Felsenstein, 1989).

The new isolate consisted of Gram-positive, non-sporeforming, non-acid-fast, straight to slightly curved rods. After $48 \mathrm{~h}$ anaerobic incubation on fastidious anaerobe agar (LAB M) with $5 \%$ horse blood, colonies were $<1 \mathrm{~mm}$ in diameter, convex, smooth, entire-edged, grey or white and weakly $\beta$-haemolytic. On primary culture, the isolate grew well under anaerobic conditions, poorly in air plus $5 \% \mathrm{CO}_{2}$ and not at all in air. After repeated subcultures, weak growth under aerobic conditions was achieved. In air and in air plus $\mathrm{CO}_{2}$, colonies were smaller but had a similar morphology to that seen under anaerobic conditions. The organism was catalase-negative and produced L-lactic acid as the major product of glucose metabolism, together with minor amounts of acetic acid. Using the API Rapid ID 32Strep system, the isolate produced acid from ribose but not from D-arabitol, L-arabinose, cyclodextrin, glycogen, lactose, mannitol, maltose, melibiose, melezitose, methyl $\beta$-Dglucopyranoside, pullulan, raffinose, sorbitol, sucrose, tagatose or trehalose. The organism hydrolysed hippurate and was $\beta$-glucuronidase-positive. All other tests in the API Rapid ID 32Strep system were negative. Using the API Coryne system, the isolate produced acid from glucose, ribose, maltose and sucrose. Acid formation from the latter two substrates was at variance with the results from the API Rapid ID 32Strep system. With the API Coryne system, the organism tested positive for $\beta$-glucuronidase and urease production; all other enzyme tests were negative using this test kit. The code generated using the API Coryne system corresponded to 0201321. Using the API Rapid ID 32A system, the isolate gave positive reactions for arginine arylamidase, $\beta$-glucuronidase, proline arylamidase and urease; no other enzyme activities were detected with this system. Employing the API ZYM system, only $\beta$-glucuronidase activity was positive. On Christensen's urea agar, a rapid positive reaction was observed.

The long-chain cellular fatty acid composition of the isolate was examined and found to consist of $\mathrm{C}_{10: 0}(1 \%), \mathrm{C}_{12: 0}$ $(2 \%), \mathrm{C}_{14: 0}(19 \%), \mathrm{C}_{16: 0}(30 \%), \mathrm{C}_{16: 1}(7 \%), \mathrm{C}_{18: 0}(7 \%)$ and $\mathrm{C}_{18: 1} \omega 9 \mathrm{c}(34 \%)$. This fatty acid composition is consistent with that found in species of the genera Actinomyces, Arcanobacterium and Actinobaculum. Based on its cellular morphology and general biochemical reactions, the unidentified organism did not correspond to any recognized species within the genus Actinomyces or related genera (Schaal, 1986, 1998). To establish the phylogenetic affinities of the organism, its almost-complete 16S rRNA gene sequence was determined. Sequence database searches showed that the organism was related to the high- $G+C$, Gram-positive Actinobacteria. The organism had highest sequence similarity to members of the genera Actinobaculum and Arcanobacterium, with species of the genera Actinomyces and Mobiluncus being more distantly related (data not shown). Neighbour-joining treeing analysis showed that the novel isolate possessed a significant phylogenetic affinity with the genus Actinobaculum (Fig. 1). The clustering of the isolate with the Actinobaculum group was supported by a bootstrap resampling value of $90 \%$. Sequence similarities between the novel isolate and Actinobaculum schaalii and Actinobaculum suis were respectively 93.3 and $92 \cdot 0 \%$.

It is apparent from comparative $16 \mathrm{~S}$ rRNA gene sequencing that the isolate recovered from human urine represents a hitherto unknown Actinobaculum species. Only two members of this genus, Actinobaculum schaalii and Actinobaculum suis, have been described at the time of writing (Lawson et al., 1997). It is evident from the treeing analysis that the bacterium represents a novel subline,

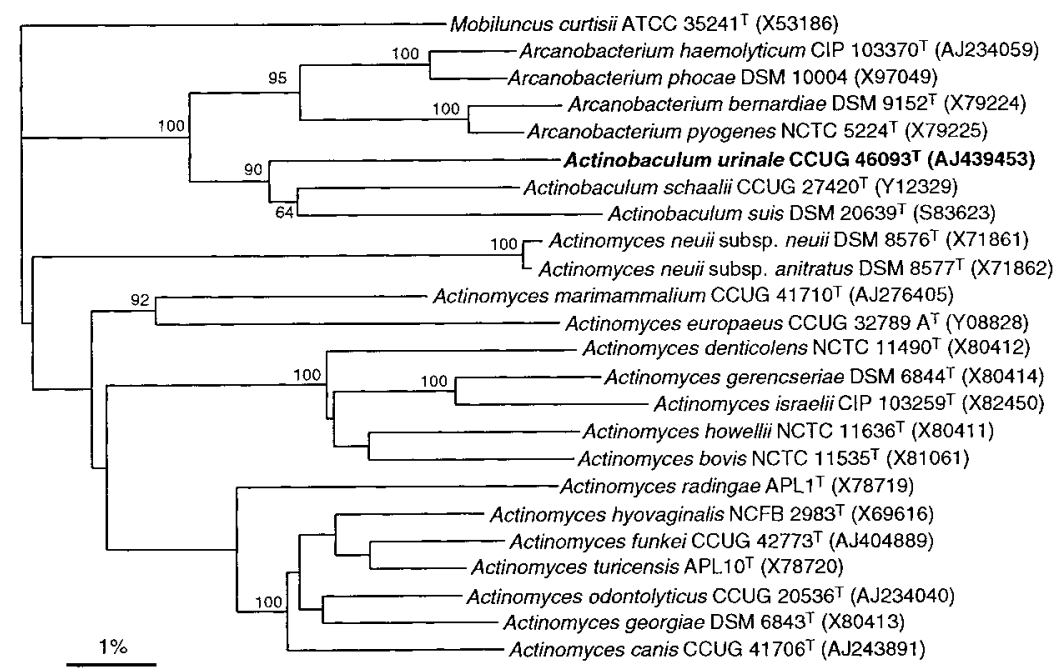

Fig. 1. Unrooted neighbour-joining tree showing the phylogenetic relationships of Actinobaculum urinale sp. nov. The tree was based on a comparison of approximately 1327 nt. Bootstrap values, expressed as percentages of 500 replications, are given at branching points. Bar, $1 \%$ sequence divergence. 
branching at the base of the Actinobaculum cluster. Sequence divergence values of $>5 \%$ between the unidentified isolate and Actinobaculum schaalii and Actinobaculum suis, however, show that the phylogenetic affinity is not particularly close and that the novel isolate merits separate species status. The separateness of the novel isolate is also very evident from biochemical criteria. Biochemically, the organism is quite different from Actinobaculum schaalii and Actinobaculum suis, and can be readily distinguished from all other Actinomyces-like species. Thus, based on the results of the reported taxonomic study, we propose that the novel isolate from urine should be classified in the genus Actinobaculum, as Actinobaculum urinale sp. nov. Tests that are useful for distinguishing Actinobaculum urinale from other species of the same genus are shown in Table 1. Although only a single strain of Actinobaculum urinale is currently known, we consider that the formal description of this species, together with biochemical criteria to aid its identification, will facilitate its recognition in the future in clinical laboratories, thereby permitting the recovery of additional strains of this species and an evaluation of its distribution, clinical prevalence and possible significance.

\section{Description of Actinobaculum urinale sp. nov.}

Actinobaculum urinale (u.ri.na'le. N.L. neut. adj. urinale pertaining to urine).
Cells are straight to slightly curved Gram-positive rods. Branching is not observed. Cells are non-acid-fast and non-spore-forming. After $48 \mathrm{~h}$ anaerobic incubation on fastidious anaerobe agar with $5 \%$ horse blood, colonies are $<1 \mathrm{~mm}$ in diameter, convex, smooth, entire-edged, grey or white and weakly $\beta$-haemolytic. Facultatively anaerobic and catalase-negative. Lactic acid is the major end product of glucose metabolism, together with minor amounts of acetic acid. Using the commercially available API systems, acid is produced from glucose and ribose; acid production from maltose and sucrose is variable and dependent on the test system used. Acid is not formed from D-arabitol, L-arabinose, cyclodextrin, glycogen, lactose, mannitol, mannose, melibiose, melezitose, methyl $\beta$-D-glucopyranoside, pullulan, raffinose, sorbitol, tagatose, trehalose or D-xylose. Hippurate is hydrolysed but gelatin and aesculin are not. Arginine arylamidase, $\beta$-glucuronidase and proline arylamidase are produced and urease may or may not be detected. Alanine-phenylalanine-proline arylamidase, arginine dihydrolase, acid phosphatase, alkaline phosphatase, alanine arylamidase, arginine arylamidase, $\alpha$-arabinosidase, chymotrypsin, trypsin, cysteine arylamidase, esterase C-4, ester lipase C- $8, \alpha$-fucosidase, $\alpha$-galactosidase, $\beta$ galactosidase, $\beta$-galactosidase-6-phosphate, $\alpha$-glucosidase, $\beta$-glucosidase, glycyl tryptophan arylamidase, glutamic acid decarboxylase, glutamyl glutamic acid arylamidase, glycine arylamidase, histidine arylamidase, leucine arylamidase,

Table 1. Commercial tests that are useful for distinguishing Actinobaculum urinale sp. nov. from Actinobaculum schaalii and Actinobaculum suis

A. schaalii strains tested were CCUG 27420 ${ }^{\mathrm{T}}$, CCUG 19698, CCUG 32296, CCUG 29359 and CCUG 36567. +, Positive; -, negative; $\mathrm{v}$, variable.

\begin{tabular}{|c|c|c|c|}
\hline Test & A. urinale CCUG $46093^{\mathrm{T}}$ & A. schaalii $(n=5)$ & A. suis CCUG $19206^{\mathrm{T}}$ \\
\hline \multicolumn{4}{|l|}{ API Rapid ID 32Strep system } \\
\hline \multicolumn{4}{|l|}{ Acid from: } \\
\hline Maltose & - & + & - \\
\hline Sucrose & - & $\mathrm{v}$ & - \\
\hline Alkaline phosphatase & - & - & + \\
\hline$\beta$-Glucuronidase & + & - & + \\
\hline Pyroglutamic acid arylamidase & - & + & + \\
\hline \multicolumn{4}{|l|}{ API Rapid ID 32A system } \\
\hline \multicolumn{4}{|l|}{ Production of: } \\
\hline$\beta$-Glucuronidase & + & - & + \\
\hline Leucine-glycine arylamidase & - & + & + \\
\hline Pyroglutamic acid arylamidase & - & + & + \\
\hline Tyrosine arylamidase & - & + & + \\
\hline Urease & + & - & + \\
\hline
\end{tabular}


leucyl glycine arylamidase, lipase C-14, $\alpha$-mannosidase, $\beta$-mannosidase, $N$-acetyl- $\beta$-glucosaminidase, phosphoamidase, phenylalanine arylamidase, pyroglutamic acid arylamidase, pyrazinamidase, serine arylamidase, tyrosine arylamidase and valine arylamidase are not detected. Acetoin is not produced. Indole-negative. Nitrate is not reduced to nitrite. The cellular fatty acids are of the straightchain saturated and monounsaturated types, with $\mathrm{C}_{14: 0}$, $\mathrm{C}_{16: 0}, \mathrm{C}_{16: 1}, \mathrm{C}_{18: 0}$ and $\mathrm{C}_{18: 1} \omega 9 c$ predominating.

The type strain, CCUG $46093^{\mathrm{T}}\left(=\mathrm{CIP} 107424^{\mathrm{T}}\right)$, was isolated from human urine. Habitat is not known.

\section{References}

Collins, M. D., Hoyles, L., Kalfas, S., Sundquist, G., Monsen, T., Nikolaitchouk, N. \& Falsen, E. (2000). Characterization of Actinomyces isolates from infected root canals of teeth: description of Actinomyces radicidentis sp. nov. J Clin Microbiol 38, 3399-3403.

Felsenstein, J. (1989). PHYLIP - Phylogeny inference package (version 3.2). Cladistics 5, 164-166.

Hall, V., O'Neill, G. L., Magee, J. T. \& Duerden, B. I. (1999). Development of amplified 16S ribosomal DNA restriction analysis for identification of Actinomyces species and comparison with pyrolysis-mass spectrometry and conventional biochemical tests. J Clin Microbiol 37, 2255-2261.

Hall, V., Talbot, P. R., Stubbs, S. L. \& Duerden, B. I. (2001). Identification of clinical isolates of Actinomyces species by amplified 16S ribosomal DNA restriction analysis. J Clin Microbiol 39, 3555-3562.
Holdeman, L. V., Cato, E. P. \& Moore, W. E. C. (1977). Anaerobe Laboratory Manual, 4th edn. Blacksburg, VA: Virginia Polytechnic Institute and State University.

Kämpfer, P. \& Kroppenstedt, R. M. (1996). Numerical analysis of fatty acid patterns of coryneform bacteria and related taxa. Can J Microbiol 42, 989-1005.

Lawson, P. A., Falsen, E., Åkervall, E., Vandamme, P. \& Collins, M. D. (1997). Characterization of some Actinomyces-like isolates from human clinical specimens: reclassification of Actinomyces suis (Soltys and Spratling) as Actinobaculum suis comb. nov. and description of Actinobaculum schaalii sp. nov. Int J Syst Bacteriol 47, 899-903.

Nikolaitchouk, N., Hoyles, L., Falsen, E., Grainger, J. M. \& Collins, M. D. (2000). Characterization of Actinomyces isolates from samples from the human urogenital tract: description of Actinomyces urogenitalis sp. nov. Int J Syst Evol Microbiol 50, 1649-1654.

Rasmussen, S. W. (1995). DNATools, a software package for DNA sequence analysis. Carlsberg Laboratory, Copenhagen.

Schaal, K. P. (1986). Genus Actinomyces. In Bergey's Manual of Systematic Bacteriology, vol. 2, pp. 1383-1418. Edited by P. H. A. Sneath, N. S. Mair, M. E. Sharpe \& J. G. Holt. Baltimore: Williams \& Wilkins.

Schaal, K. P. (1998). Actinomycoses, actinobacillosis and related diseases. In Topley and Wilson's Microbiology and Microbial Infections, 9th edn, vol. 3, pp. 777-798. Edited by W. J. Hausler, Jr \& M. Sussman. London: Edward Arnold.

Wegienek, J. \& Reddy, A. C. (1982). Taxonomic study of "Corynebacterium suis" Soltys and Spratling: proposal of Eubacterium suis (nom. rev.) comb. nov. Int J Syst Bacteriol 32, 218-228.

Wüst, J., Stubbs, S., Weiss, N., Funke, G. \& Collins, M. D. (1995). Assignment of Actinomyces pyogenes-like (CDC coryneform group E) bacteria to the genus Actinomyces as Actinomyces radingae sp. nov. and Actinomyces turicensis sp. nov. Lett Appl Microbiol 20, 76-81. 